\title{
Leczenie złamań kości krzyżowej za pomocą cementu kostnego u pacjentów z osteoporozą
}

\author{
Treatment of sacral insufficiency fractures by injection o bone cement in patients \\ with osteoporosis
}

\author{
Robert Gasik, Łukasz Kubaszewski, Sławomir Mihułka \\ Klinika i Poliklinika Neuroortopedii i Neurologii Instytutu Reumatologii im. prof. dr hab. med. Eleonory Reicher w Warszawie
}

Słowa kluczowe: osteoporoza, kość krzyżowa, złamanie, sakroplastyka.

Key words: osteoporosis, sacral, fracture, sacroplasty.

\begin{abstract}
Streszczenie
Złamania w obrębie kręgosłupa są najczęściej występującymi złamaniami u chorych z osteoporozą. Najczęstszą lokalizacją złamań są trzony kręgów odcinka piersiowo-lędźwiowego oraz części piersiowej kręgosłupa. Stosunkowo rzadko występują złamania w obrębie kości krzyżowej. W przypadku stwierdzenia złamań w obrębie kości krzyżowej zasady leczenia są podobne do postępowania w przebiegu złamań kompresyjnych trzonów kręgowych o innej lokalizacji. Współczesne zasady leczenia złamań osteoporotycznych kości krzyżowej, poza leczeniem farmakologicznym zmieniającym proces przebudowy tkanki kostnej, rehabilitacją i stosowaniem gorsetu, zakładają możliwość wykonania przezskórnej plastyki kości krzyżowej za pomocą cementu kostnego, tzn. sakroplastyki.

Zabieg ten poprzez zmniejszenie dolegliwości bólowych pozwala na skrócenie czasu unieruchomienia, który wtórnie nasila proces utraty gęstości tkanki kostnej. Sakroplastykę można wykonać w znieczuleniu miejscowym z analgosedacją, co jest istotną zaletą u osób w podeszłym wieku i z współwystępowaniem innych schorzeń. Najważniejszym przeciwwskazaniem do wykonania zabiegu w obrębie kości krzyżowej jest naruszenie ścian kanału krzyżowego i otworów kości krzyżowej, które zagraża przemieszczeniem cementu. Mimo że sakroplastyka jest relatywnie bezpieczną procedurą, mogą wystąpić powikłania, z których najpoważniejsze to: wyciek cementu do kanału kręgowego, zatorowość płucna lub zatory naczyń mózgowych spowodowane wyciekiem cementu. Po uwzględnieniu przeciwwskazań do wykonywania tego zabiegu sakroplastyka przedstawia się jako przydatna procedura stosowana w leczeniu złamań kości krzyżowej u pacjentów z osteoporozą.
\end{abstract}

\section{Sum mary}

Vertebral body fractures are most commonly observed fractures of the patients with osteoporosis. Most often are observed in the thoraco-lumbar junction and thoracic spine. It is rather seldom observed in the sacral bone. In case where sacral fracture was diagnosed in patient with osteoporosis, the available treatment procedures are similar to those used in the other vertebral compression fractures. Contemporary treatment protocol along with pharmacotherapy to slow down the bone turn-over, rehabilitation, orthotic treatment, advocates also for percutaneous injection with the bone cement of the sacral bone - sacroplasty.

Sacroplasty procedure gives chance to decrease the pain related to the fracture, limiting the immobilisation time, directly related to the bone density loss. The procedure can be performed in local anaesthesia with sedation, which is beneficial for elderly patients with comorbidities. Contraindications for it are similar to those underlined in the rest of the spine: posterior wall fracture endangering the cement leakage to the spinal canal, neurological symptoms aggravated by the fracture occurrence, as well the general ones. In spite the sacroplasty is to be considered low risk procedures, serious complication might be observed. The most serious are cement leakage into the spinal canal or pulmonary or central nervous system embolisation with the cement. Sacroplasty, similarly to the vertebroplasty in the thoracic or lumbar spine might be a suitable procedure in osteoporotic fracture treatment of the sacrum.

\section{Adres do korespondencji:}

prof. nadzw. dr hab. n. med. Robert Gasik, Klinika Neuroortopedii i Neurologii, Instytut Reumatologii, ul. Spartańska 1, 02-637 Warszawa, tel. +48228444241 wew. 375, e-mail: robert.gasik@ir.ids.pl

Praca wpłynęła: 30.10 .2012 r. 


\section{Wstęp}

Osteoporoza to jedna z głównych przyczyn złamań kręgosłupa [1]. Spośród wszystkich złamań powstających w przebiegu osteoporozy złamania kompresyjne kręgosłupa stanowią ok. 27\% [1]. W większości przypadków są to złamania, które nie mają charakteru urazowego. Złamaniem kompresyjnym nieurazowym można określić zmniejszenie wysokości kręgu o 20\% lub co najmniej 4 mm pod wpływem działania sit, które nie spowodowałyby złamania kości o prawidłowej budowie [2]. Złamaniom tym rzadko towarzyszą objawy kompresji struktur nerwowych kręgosłupa. Potwierdzają to dane statystyczne, z których wynika, że tylko u 30\% pacjentów ze złamaniami kompresyjnymi trzonów kręgowych występują objawy kliniczne [3].

Złamania kompresyjne kręgosłupa towarzyszące osteoporozie dzieli się na podstawie różnych kryteriów. Jednym z kryteriów jest lokalizacja złamania. Najczęściej złamania dotyczą trzonów kręgów Th7, Th8, Th12 i L1 [4]. Złamaniom kompresyjnym może także ulegać kość krzyżowa. Złamania te są jedno- lub obustronne. Bayley i wsp. wskazują na porównywalną liczebność grup pacjentów ze złamaniami jedno- lub dwustronnymi kości krzyżowej [5].

Leczenie stosowane u większości pacjentów ze złamaniami kości krzyżowej ma charakter zachowawczy [5]. Efekty leczenia zachowawczego u dużego odsetka pacjentów są jednak niezadowalające. Na negatywną ocenę rezultatów leczenia zachowawczego tych złamań wpływa przedłużające się ograniczenie aktywności ruchowej, które jest wywołane bólem [5]. Na skutek tego pogłębia się

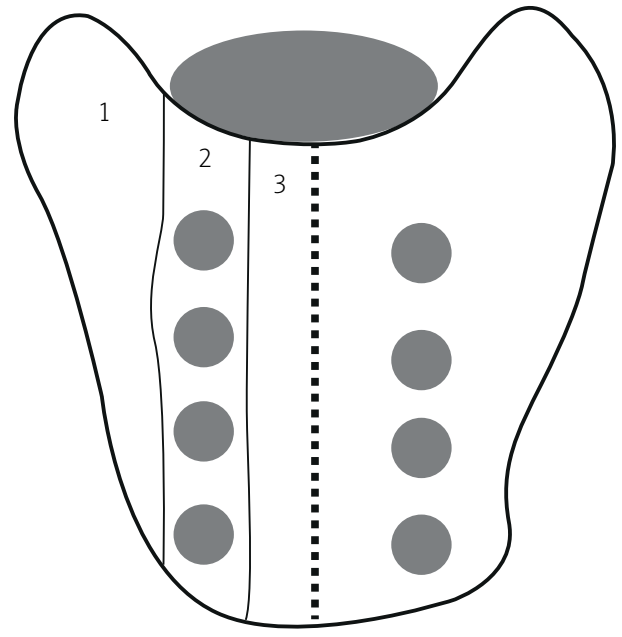

Ryc. 1. Podział złamań urazowych kości krzyżowej wg Denisa [10]. Opis w tekście.

Fig. 1. Classification of traumatic fractures of the sacrum by Denis [10]. The description is in the text. osteoporoza oraz rozwijają się inne powikłania związane z przedłużającym się ograniczeniem dotychczasowej aktywności ruchowej. Wynikiem znacznego ograniczenia aktywności ruchowej jest także postępujący ubytek masy kostnej o ok. 0,5\% co 7 dni [6].

Rezultaty leczenia operacyjnego wykonywanego w znieczuleniu ogólnym i polegającego na ustabilizowaniu złamania za pomocą materiałów zespalających nie zawsze są jednak zadowalające dla pacjenta. Wynika to z powikłań towarzyszących znieczuleniu ogólnemu i skutków działania implantów na osłabioną strukturę kości u pacjentów z osteoporozą.

Alternatywą dla pacjentów ze złamaniami kości krzyżowej towarzyszącymi osteoporozie są zabiegi sakroplastyki. Po raz pierwszy zabieg sakroplastyki opisał Garant w 2002 r. [7]. Od tego czasu metoda jest stosowana w przypadku złamań, którym towarzyszy przewlekający się ból niereagujący na zachowawcze metody leczenia.

\section{Wskazania do zabiegu}

Wskazania do zabiegu są ustalane z uwzględnieniem charakteru złamania kości krzyżowej, występowania ubytkowych objawów neurologicznych oraz czasu utrzymywania się zespołu bólowego. W celu ustalenia charakteru złamania wykonuje się badania radiologiczne i obrazowe. Najczęściej zlecane badania radiologiczne są wykonywane w projekcji przednio-tylnej i bocznej kości krzyżowej [8, 9]. Korzystając z podziału złamań urazowych opisanych przez Denisa, ocenia się lokalizację złamania w projekcji przednio-tylnej (ryc. 1) [10].

Szczelina złamania w strefie pierwszej nie przebiega z uszkodzeniem struktur nerwowych - ten typ złamania występuje najczęściej. Złamanie w strefie drugiej może dawać objawy związane z kompresją korzeni nerwowych. Złamanie w strefie trzeciej może przebiegać z uszkodzeniem struktur nerwowych znajdujących się w kanale krzyżowym. Szczelina złamania w kształcie litery U lub inne odmiany tego złamania przebiegają przez strefy trzecią i drugą, co wiąże się z potencjalnym uszkodzeniem struktur nerwowych kanału kręgowego. Na podstawie klisz bocznych radiogramów ustala się typy złamań wg klasyfikacji Roy-Camille i Strange-Vognsen (ryc. 2) [11, 12].

Pewnej kwalifikacji do zabiegów sakroplastyki podlegają złamania w strefie pierwszej wg klasyfikacji Denisa [10]. Kwalifikacja do zabiegu sakroplastyki w przypadku innych rodzajów złamań musi być rozpatrywana indywidualnie. W większości złamania kości krzyżowej w przebiegu osteoporozy kwalifikują się do grupy, w której można wykonać sakroplastykę.

Badania rentgenowskie (RTG) w wielu przypadkach nie potwierdzają złamania kompresyjnego kości krzyżowej. W przypadkach tych rozstrzygające jest badanie scynty- 

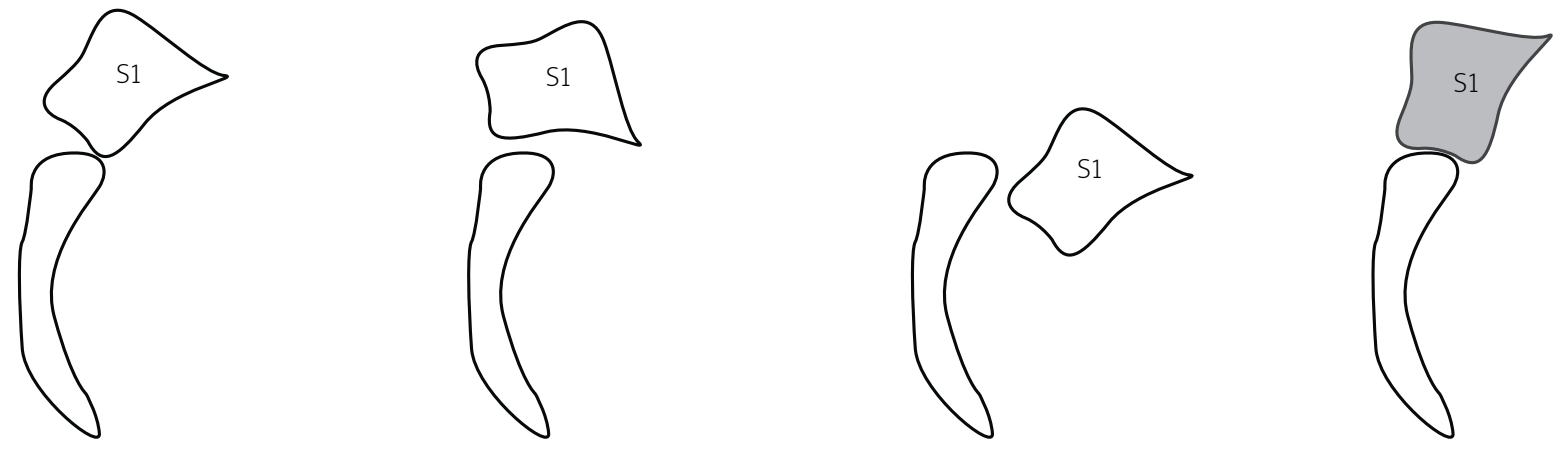

Ryc. 2. Podział złamań urazowych kości krzyżowej wg Roy-Camille i Strange-Vognsen [11, 12]. Roy-Camille dzieli złamania na trzy grupy. Grupa I to niewielka zgięciowa deformacja kości krzyżowej. W grupie II dochodzi do małego przemieszczenia odłamu i kifotycznego zgięcia kości krzyżowej. W grupie III dochodzi do znacznego przemieszczenia odłamu. Dodatkową IV grupę złamań opisał Strange-Vognsen. Do grupy tej zaliczane są złamania trzonu kręgu S1. Złamanie ma charakter kompresyjny lub trzon może być rozkawałkowany pod wpływem sił działających w długiej osi kości krzyżowej.

Fig. 2. Classification of traumatic fractures of the sacrum by Roy-Camille and Strange-Vognsen [11, 12]. RoyCamille divides fractures into three groups. Group I is a small flexion deformity of the sacrum. In group II, there is a small dislocation of the fragment with kyphotic bending of the sacrum. In the third group there is a significant dislocation of the proximal fragment. Additional IV fracture group was described by StrangeVognsen. This group includes S1 vertebra fracture. The fracture may be either of compression nature and vertebra can be fragmented by forces in the long axis of the sacrum.

graficzne lub obrazowe kości krzyżowej (rezonans magnetyczny, tomografia komputerowa) [8, 9].

\section{Przeciwwskazania do wykonania zabiegu}

Przeciwwskazania do wykonywania zabiegów sakroplastyki można podzielić na trzy grupy. Wynikają one z rodzaju złamania (grupa A), objawów dodatkowych (grupa B) i chorób towarzyszących (grupa C). W grupie A najważniejszym przeciwwskazaniem do wykonania zabiegu są złamania, w których dochodzi do naruszenia ścian kanału krzyżowego i otworów kości krzyżowej. W przypadku takich złamań cement medyczny (polimetylmetakrylat - PMMA) podawany podczas zabiegu może wydostawać się do miejsc, w których znajdują się struktury nerwowe kręgosłupa. Może wówczas dochodzić do powstawania neurologicznych objawów ubytkowych i nasilenia bólu. W grupie B decyzję o wykonaniu zabiegu podejmuje się w zależności od rodzaju i natężenia ubytkowych objawów neurologicznych. Przeciwwskazaniem do wykonania zabiegu sakroplastyki są objawy kompresji struktur nerwowych kanału kości krzyżowej oraz objawy neurologiczne pojawiające się w przebiegu złamania. W grupie C przeciwwskazaniami do zabiegu sakroplastyki są: infekcje ogólnoustrojowe i miejscowe, zmiany skórne w miejscu wykonywania zabiegu, np. odleżyna, i alergie na cement kostny PMMA, koagulopatie oraz inne choroby uniemożliwiające zastosowanie analgezji i sedacji.

\section{Technika wykonywania zabiegu}

Zabieg wykonuje się w znieczuleniu miejscowym i analgosedacji. Technika wykonania zabiegu polega na aplikacji 4-20 cm³ PMMA w okolice szczeliny złamania kości krzyżowej (ryc. 3 i 4). W praktyce klinicznej wykorzystuje się dostęp prostopadły i równoległy do długiej osi kości krzyżowej. Dostęp równoległy polega na jednym wkłuciu wykonywanym wzdłuż kości krzyżowej. Dostęp prostopadły polega na co najmniej dwóch wkłuciach wykonanych prostopadle do długiej osi kości krzyżowej. W obydwu technikach cement podaje się do masywów bocznych (skrzydet) kości krzyżowej. Na wybór zastosowanego dostępu wpływa typ złamania.

Kilka godzin po zabiegu pacjent może podejmować aktywność fizyczną. Średni czas pobytu pacjenta w szpitalu nie przekracza 3 dni.

\section{Powikłania po zabiegu}

Potencjalnym powikłaniem wszystkich zabiegów chirurgicznych naruszających barierę skóry są infekcje i krwawienia. Podczas wprowadzania igły może także dochodzić do uszkodzenia struktur układu nerwowego przebiegających w obrębie kości krzyżowej oraz naczyń przebiegających w sąsiedztwie kości krzyżowej [13]. Inną grupą powikłań jest wyciekanie PMMA do kanału kości krzyżowej i otworów oraz poza kość krzyżową [14]. Cement PMMA może także przedostawać się do układu naczyniowego, 

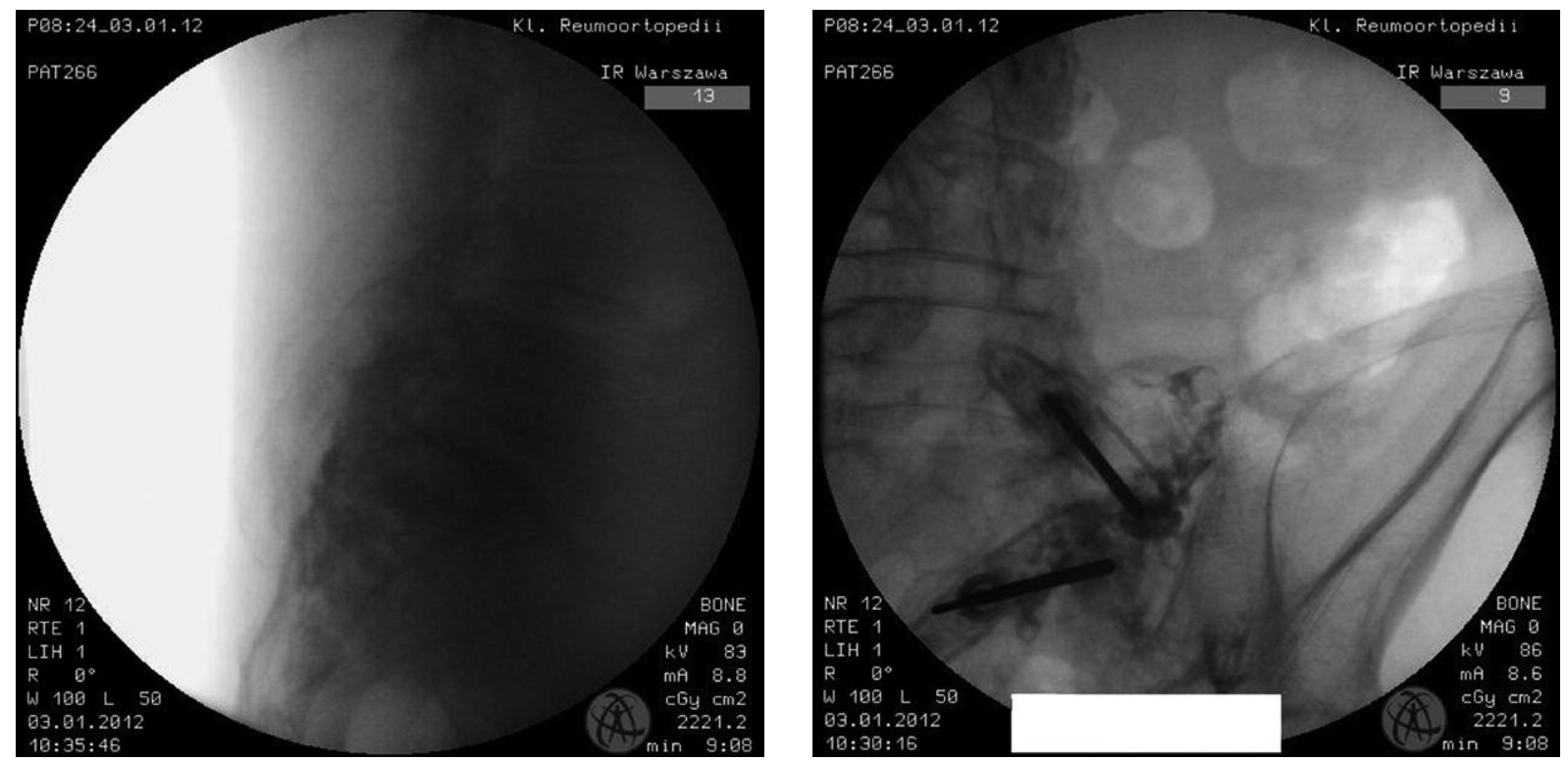

Ryc. 3 i 4. Obraz radiologiczny kości krzyżowej w projekcji bocznej (ryc. 3) i przednio-tylnej (ryc. 4) u pacjentki po zabiegu sakroplastyki wykonanym z powodu złamania w przebiegu osteoporozy.

Fig. 3 and 4. X-ray images of the sacrum in a lateral projection (fig. 3) and AP projection (fig. 4) in a patient after sacroplasty because of an osteoporotic fracture.

powodując zatorowość płucną [14]. Opisywane są pojedyncze przypadki zatorowości naczyń mózgowych i nerkowych [14]. Częstość występowania wszystkich powikłań jest bardzo mała i obejmuje do 3\% wykonywanych zabiegów [15].

\section{Wnioski}

Zabieg sakroplastyki jest uzupełnieniem dotychczas stosowanych metod leczenia złamań kości krzyżowej w przebiegu osteoporozy. Najważniejszym wskazaniem do wykonania zabiegu jest ból niepoddający się zachowawczym metodom leczenia [13]. Nowsze prace wykazują efektywność przeciwbólową sakroplastyki [5]. W literaturze tematu podawane są dwie potencjalne przyczyny ustępowania bólu po wykonaniu zabiegu sakroplastyki. Pierwszą z nich jest stabilizacja złamania. W wyniku tego zanikają mikroruchy w szczelinie złamania $[16,17]$. Druga teoria za przyczynę ustępowania bólu uznaje miejscowe działanie PMMA na wolne zakończenia nerwowe znajdujące się w sąsiedztwie szczeliny złamania, odpowiadające za powstawanie sygnału bólowego [16, 17]. Odległe skutki zabiegu wymagają prowadzenia dalszych obserwacji i badań.

\section{Autorzy deklaruja brak konfliktu interesów.}

\section{Piśmiennictwo}

1. Burger R, Dawson-Hughes B, Solomon DH, et al. Incidence and economic burden of osteoporosis-related fractures in the United States, 2005-2025. J Bone Miner Res 2007; 22: 465-475.
2. Black DM, Palermo L, Nevitt MC, et al. The Study of Osteoporotic Fractures Research Group Defining incident vertebral deformity: a prospective comparison of several approaches. J Bone Miner Res 1999; 14: 90-101.

3. Lindsay R, Silverman $\mathrm{SI}$, Cooper C, et al. Risk of new vertebral fracture in the year following a fracture. JAMA 2001; 285: 320-323.

4. Nevitt MC, Ross PD, Palermo L, et al. Association of prevalent vertebral fracture, bone density, and alendronate treatment with incident vertebral fractures: effect of number and spinal location of fractures. Bone 1999; 25: 613-619.

5. Bayley E, Srinivas S, Boszczyk BM. Clinical outcomes of sacroplasty in sacral insufficiency fractures: a review of the literature. Eur Spine J 2009; 18: 1266-1271.

6. Rao RD, Singrakhia MD. Painful osteoporotic vertebral fracture. Pathogenesis, evaluation, and roles of vertebroplasty and kyphoplasty in its management. J Bone Joint Surg Am 2003; 85A: 2010-2022.

7. Garant M. Sacroplasty: a new treatment for sacral insufficiency fracture. J Vasc Interv Radiol 2002; 13: 1265-1267.

8. Ries T. Detection of osteoporotic sacral fractures with radionuclides. Radiology 1983; 146: 783-785.

9. Schneider R, Yacovone J, Ghelman B. Unsuspected sacral fractures: detection by radionuclide bone scanning. AJR Am J Roentgenol 1985; 144: 337-341.

10. Denis F, Davis S, Comfort T. Sacral fractures: an important problem. Retrospective analysis of 236 cases. Clin Orthop Relat Res 1988; 227: 67-81.

11. Roy-Camille R, Saillant G, Gagna G, et al. Transverse fracture of the upper sacrum: suicdal jumper's fracture. Spine 1985; 10: 838-845.

12. Strange-Vognsen HH, Lebech A. An unusual type of fracture in the upper sacrum. J Ortho Trauma 1991; 5: 200-203. 
13. Frey ME, DePalme MJ, Cifu DX, et al. Percutaneous sacroplasty for osteoporotic sacral insufficiency fractures: a prospective, multicenter, observational pilot study. Spine J 2008; 8: 367-373.

14. Gjertsen O, Schellhorn T, Nakstad PH. Fluoroscopy-guided sacroplasty: special focus on preoperative planning from three-dimensional computed tomography. Acta Radiol 2008; 49: 1042-1048.

15. Lin WC, Cheng TT, Lee YC, et al. New vertebral osteoporotic compression fractures after percutaneous vertebroplasty; retrospective analysis of risk factors. J Vasc Interv Radiol 2008; 19 : 225-231.

16. Anderson DE, Cotton JR. Mechanical analysis of percutaneous sacroplasty using CT image based finite element model. Med Eng Phys 2007; 29: 316-325.

17. Belkoff SM, Molloy S. Temperature measurement during polymerization of polymethylmethacrylate cement used for vertebroplasty. Spine 2003; 28: 1555-1559. 